EUS as compared to asymptomatic patients (78\% vs 22\%), but this difference was not found to be statistically significant. Conclusion Performing EUS and ERCP in single sessions is a safe and effective strategy. Careful selection of patients for single session EUS-ERCP can avoid unnecessary high risk ERCP procedures. Patients who had planned combined procedure for suspected stone disease did not require significant extra time as compared to ERCP alone. We suggest that all ERCP requests should be reviewed by experienced endoscopists and prior EUS should be considered in selected patients.

\section{PWE-064 BONE DENSITY ASSESSMENT IN CHRONIC PANCREATITIS (CP) : ARE WE SCREENING OUR PATIENTS APPROPRIATELY?}

${ }^{1}$ Bidour Awadelkarim*, 'Debasis Majumdar, ${ }^{1}$ Charlotte Morrison, ${ }^{2} \mathrm{JW}$ Tan, ${ }^{1}$ Vikramjit Mitra. ${ }^{1}$ South Tees NHS Foundation Trust, Middlesbrough, UK; ${ }^{2}$ Final Year Student, Medical School, Newcastle, UK

\subsection{6/gutjnl-2019-BSGAbstracts.295}

Patients with CP are at increased risk of low bone density because of multiple factor including malabsorption of vitamin $\mathrm{D}$ and calcium, poor diet, alcoholism and smoking [1].Recent NICE guidelines recommend offering bone density assessment to all patients with $\mathrm{CP}$ every 2 years [2]

Aims and methods A retrospective audit was carried out to investigate the incidence of bone density abnormality in all patients diagnosed with chronic pancreatitis between September 2014 and April 2018 in our organisation. Data was collected on patient demographics, social history, DEXA scan assessment and laboratory investigations.

Results 123 patients [median age 62 years, male-female ratio 1.7:1] were diagnosed with CP during this period. The aetiology of CP were as follows: alcohol 16.9\% ( $n=26)$, smoking $4.8 \%(n=6)$, smoking and alcohol combined 40.6\% ( $n=50$ ), gallstone disease $7.3 \%(n=9)$, hereditary pancreatitis $1.6 \%$ ( $\mathrm{n}=2$ ) and idiopathic in 23.5\% $(\mathrm{n}=29)$.

\begin{tabular}{|c|c|c|c|}
\hline DEXA Scan Results & $\begin{array}{l}\text { Normal } \\
(n=13)\end{array}$ & $\begin{array}{l}\text { Osteopaenia } \\
(\mathrm{n}=21)\end{array}$ & $\begin{array}{l}\text { Osteoporosis } \\
(n=25)\end{array}$ \\
\hline $\begin{array}{l}\text { Vitamin D (25-OH D): Adequate/ } \\
\text { optimum ( }>50 \mathrm{~nm} / / \mathrm{L}) \\
\text { Insufficient Deficient ( }<25 \mathrm{nmol} / \mathrm{L}) \\
\text { Not measured }\end{array}$ & $\begin{array}{l}77 \%(n \\
=10) \\
33 \%(n=3 \\
) \\
0 \%(n=0 \\
)\end{array}$ & $\begin{array}{l}81 \%(n=17) \\
9.5 \%(n=2) \\
9.5 \%(n=2)\end{array}$ & $\begin{array}{l}72 \%(n=18) \\
16 \%(n=4) \\
12 \%(n=3)\end{array}$ \\
\hline $\begin{array}{l}\text { PTH } \\
\text { Normal ( } 12-72 \mathrm{ng} / \mathrm{L}) \\
\text { High } \\
\text { Not Measured }\end{array}$ & $\begin{array}{l}7.7 \%(n= \\
1) \\
7.7 \%(n \\
=1) \\
84.6 \%(n \\
=11)\end{array}$ & $\begin{array}{l}24 \%(n=5) \\
4.8 \%(n=1) \\
71.2 \%(n=15)\end{array}$ & $\begin{array}{l}52 \%(n=13) \\
0 \%(n=0) \\
48 \%(n=12)\end{array}$ \\
\hline $\begin{array}{l}\text { Calcium: } \\
\text { Normal (2.1 - } 2.6 \mathrm{mmol} / \mathrm{L}) \\
\text { High }\end{array}$ & $\begin{array}{l}100 \%(n= \\
13) \\
0 \%(n=0 \\
)\end{array}$ & $\begin{array}{l}95.2 \%(n=20 \\
4.8 \%(n=1)\end{array}$ & $\begin{array}{l}100 \%(n=25) \\
0 \%(n=0)\end{array}$ \\
\hline
\end{tabular}

$60(48.8 \%)$ patients underwent a baseline DEXA scan [23.3\% $(n=13)$ had normal bone density, 35\% $(n=21)$ had osteopenia and $41.7 \%(n=25)$ had osteoporosis]. One $(0.8 \%)$ patient had an established diagnosis of osteoporosis prior to presentation and did not undergo a DEXA scan.

Serum biochemistry levels including PTH, vitamin D and calcium levels in patients who underwent DEXA scans are summarized in the table enclosed:

Conclusion In our study only 50\% of patients underwent investigation for bone density measurement. There was a significantly high (76.7\%) incidence of bone density abnormality in patients who underwent DEXA scan highlighting the importance of this test in the long term management of $\mathrm{CP}$ patients. Following this audit, emphasis has been placed on DEXA scan assessment in all CP patients in our trust with plans for a re-audit in a year's time.

\section{REFERENCE}

1. . High prevalence of osteoporosis in patients with chronic pancreatitis: A systematic review and meta-analysis. Duggan S.N., Smyth N.D., Murphy A., MacNaughton D., O'Keefe S.J.D., Conlon K.C. (2014) Clinical Gastroenterology and Hepatology, 12 (2), pp. 219-228.

2. Guidelines, N. (2018). Pancreatitis | Guidance and guidelines | NICE. [online] Nice.org.uk. Available at: https://www.nice.org.uk/guidance/ng104

\section{PWE-065 FOUR YEARS' EXPERIENCE OF THE USE OF ENDOSCOPIC ULTRASOUND FOR THE DIAGNOSIS OF PANCREATIC MALIGNANCY}

${ }^{1}$ Chaonan Dong*, ${ }^{1}$ Mamatha Devaraj, ${ }^{2}$ Andrew Oliver, ${ }^{2}$ Frankie Rasteli, ${ }^{1}$ Debasis Majumdar, ${ }^{1}$ Jeremy Dean, ${ }^{1}$ Vikramjit Mitra. ${ }^{1}$ South Tees NHS Foundation Trust, Middlesbrough, UK; ${ }^{2}$ Newcastle University, Newcastle, UK

\subsection{6/gutjnl-2019-BSGAbstracts.296}

Introduction EUS guided tissue acquisition is an extensively used investigation to confirm the histopathological diagnosis in PB lesions. The Joint Advisory Group (JAG) suggests an adequacy rate of more than $75 \%$ for EUS-Fine Needle Aspiration cytology (FNAC) ${ }^{[1]}$. The aim of this study was to determine the diagnostic performance, adequacy of tissue acquisition and safety of EUS-FNA in PB lesions in a nonHPB centre in the UK.

Methods We carried out a retrospective audit of all patients (identified from endoscopy and pathology database) who underwent EUS-FNA between 1st January 2015 and 31st December 2018. Data collected include patient demographics, cross-sectional imaging, cytopathological diagnoses (Panc 1 to 5 based on European cytopathology classification of PB terminology ${ }^{[2]}$; neuroendocrine tumours were included in Panc 5), treatment modality, complications and 30 day procedure related mortality. Final diagnoses were confirmed from EUS FNAC, surgical resection specimen or cross-sectional imaging discussed in a MDT setting (if histology negative).

Results A total of 152 patients [mean age 66.9 years, 53.9\% females] underwent 161 PB EUS-FNAC procedures. 135 patients had a final diagnosis of cancer.

$144(89.4 \%)$ samples were deemed adequate for analysis. Sensitivity, specificity, overall accuracy, positive predictive value (PPV) and negative predictive value (NPV) were $87.7 \%$, $100 \%, 88.9 \%, 100 \%$, and $46.7 \%$ respectively [with Panc3 included as false negative in patients with cancer as final diagnosis]. These figures would improve to $94.2 \%, 100 \%, 94.8 \%$, 